\title{
TENDÊNCIAS PARA 0 ENSINO DE QUÍMICA: 0 CASO DA INTERDISCIPLINARIDADE NOS PROJETOS PEDAGÓGICOS DAS LICENCIATURAS EM QUÍMICA EM GOIÁS
}

\author{
Nyuara Araújo da Silva Mesquita* \\ Márlon H. F. B. Soares**
}

RESUMO: Para adequar o contexto da formação de professores às orientações legais da educação básica, os projetos pedagógicos de cursos (PPC) de formação de professores inseriram em seus textos a interdisciplinaridade tratando-a como um dos eixos norteadores da proposta pedagógica. A partir de tal aspecto, esta pesquisa investigou, por meio da análise textual discursiva, oito PPCs de cursos de licenciatura em Química do estado de Goiás, buscando identificar de que forma a interdisciplinaridade está caracterizada nos PPCs e se estes documentos apresentam a viabilização da formação de caráter interdisciplinar para o futuro docente. Observamos que os PPCs apresentam a interdisciplinaridade como um dos eixos de suas propostas pedagógicas, mas não oferecem suporte teórico nem indicam os caminhos metodológicos para tal adequação.

Palavras-chave: interdisciplinaridade, projeto pedagógico, licenciatura em Química

\section{TRENDS FOR CHEMISTRY TEACHING: THE CASE OF INTERDISCIPLINARITY PROJECTS OF CHEMISTRY TEACHER EDUCATION IN GOIÁS}

ABSTRACT: To adapt the context of teacher education to legal guidelines of basic education, the undergraduate program's Pedagogical Projects of Courses (PPC) inserted interdisciplinarity in their texts, treating it as one of the guiding principles of the educational proposal. From of this aspect, this research investigated, through the discursive textual analysis, eight PPCs from Chemistry graduation programs in Goias, seeking to identify how interdisciplinarity is characterized in these PPCs and analyze if these documents show a feasible interdisciplinary training for future teachers. We observed that the PPCs have the interdisciplinarity as one of their educational proposals axes, but do not offer support theoretical or methodological ways to indicate such suitability.

Keywords: interdisciplinary, teaching project, Chemistry degree

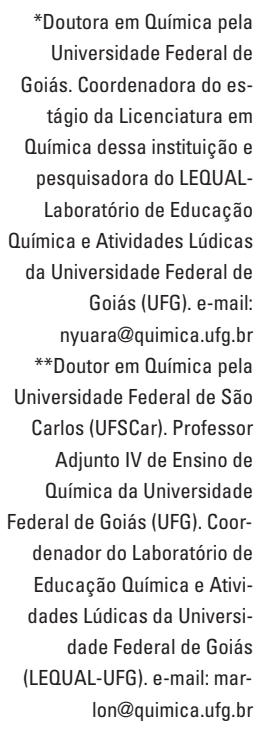


Nyuara Araújo da Silva Mesquita | Márlon H. F. B. Soares

\section{PROJETO PEDAGÓGICO DE CURSO E INTERDISCIPLINARIDADE: DIRECIONA- MENTOS LEGAIS}

Compreendemos o Projeto Pedagógico de Curso (PPC) como o resultado das intervenções de várias vozes sobre uma estrutura que é pré-estabelecida como direcionadora das práticas escolares no contexto da formação superior. A construção do documento é facultada à comunidade acadêmica, e sua elaboração, coletiva ou não, possibilita um entremeio de diversas opiniões e discursos, que resultam na caracterização da proposta pretendida.

Decorre dessa diversidade de ideias em contextos e espaços também diversos, o fato de que, apesar de haver uma estrutura pré-estabelecida para a construção do PPC, as instituições apresentam projetos diferenciados, pois são elaborados por sujeitos históricos inseridos em situações que propiciam o uso de discursos carregados de interpretações idiossincráticas que configuram novos sentidos àqueles já existentes.

Com a reforma proposta para a educação nacional a partir da LDB 9394/96 e dos Parâmetros Curriculares Nacionais na década de 1990, a interdisciplinaridade passou a ser um dos eixos mobilizadores para o ensino dos diversos conteúdos abordados na educação básica. Nesse contexto, tornaram-se necessárias mudanças na educação superior relacionadas à formação de professores para atuar na docência nas escolas de Ensino Fundamental e Médio.

Assim, os PPCs de licenciatura em Química passaram a contemplar em seus textos, a partir do final da década de 1990, questões relacionadas às tendências e propostas para educação básica, como contextualização, novas tecnologias no ensino e interdisciplinaridade, dentre outras, com o objetivo de se incluírem, na formação inicial dos licenciados, metodologias e abordagens que pudessem adequar a formação do professor às diretrizes do Ensino Médio e Fundamental.

Uma dessas tendências, a interdisciplinaridade, vem sendo utilizada em várias propostas de cursos de graduação em Química. Segundo Fazenda (2001), essa temática associada aos processos educativos tem sua origem a partir da década de 1960 na Europa, principalmente na França e Itália, em meio aos movimentos estudantis universitários, que se posicionavam contrários à excessiva especialização dos saberes por considerarem tal especialização como fator alienante da academia em relação às questões do cotidiano.

A concepção de uma proposta educacional voltada à especialização foi também considerada como restritiva e limitante para a construção do conhecimento, que não poderia mais se dar em um sentido único, pois não se adequava mais ao enfoque científico e tecnológico que se anunciava e se estabelecia como caminho sem volta para o desenvolvimento mundial.

No contexto da educação nacional, a ideia da interdisciplinaridade foi incorporada a partir da década de 1970, em um primeiro momento, apenas por força de modismo, sem a necessária definição teórica e metodológica para uma 
Tendências para o ensino de química: o caso da interdisciplinaridade nos projetos pedagógicos das licenciaturas em química em Goiás

mudança substancial em termos de realidade escolar. Encontramos pesquisa citando a influência da interdisciplinaridade na Lei 5692/71 (CARLOS, 2007):

Tendo a interdisciplinaridade chegado ao Brasil no final da década de 60, num contexto de mudanças políticas, em que o sistema educacional também passava por modificações, esta foi então rapidamente incorporada à Lei de Diretrizes e Bases da Educação Nacional de $\mathrm{N}^{\text {o }}$ 5.692/71, e acabou por influenciar a legislação brasileira. (CARLOS, 2007, p. 34)

No entanto, ao analisarmos o texto da lei citada, não encontramos referência ou associação à interdisciplinaridade, estando o enfoque principal da lei voltado para o ensino profissionalizante da educação básica e, dessa forma, não contemplando em seu texto argumentação a possibilidade de integração entre disciplinas ou conteúdos.

Para Fazenda (2001), a implementação da interdisciplinaridade no cenário educacional brasileiro deu-se a partir do seguinte movimento: em 1970 houve a procura por uma definição do termo, em 1980 aconteceu a tentativa de explicitação de um método que contemplasse a interdisciplinaridade, e, em 1990, partiu-se para a construção de uma teoria sobre a interdisciplinaridade.

Em todo esse movimento percorrido, desde o início das discussões a respeito do conceito da palavra em 1970 até a inserção legal a partir dos documentos orientadores da educação nacional na década de 1990, a interdisciplinaridade, seja como conceito, como método ou como postura, ainda não é consenso entre professores, pesquisadores e gestores participantes da construção e efetivação do processo educativo no Brasil.

Não podemos deixar de considerar que a interdisciplinaridade envolve o diálogo entre os saberes que se constroem e se encontram nos caminhos percorridos durante a formação inicial dos futuros professores. Esse diálogo se faz necessário para que esses professores, quando atuantes nas suas esferas profissionais, possam desenvolver práticas pedagógicas que sejam pensadas como possibilidades de integração entre os seus pares na escola. Essa, para nós, é a ideia-chave para se compreender a interdisciplinaridade, pois não vislumbramos a existência dessa como uma prática solitária e individual de um único sujeito em sua aula de Química.

Como podemos pensar em professores interdisciplinares na educação básica que não vivenciaram a interdisciplinaridade de seus professores formadores durante a sua graduação? É preciso refletir sobre tal questão. Os cursos de formação de professores implementam práticas pedagógicas interdisciplinares ou apenas discutem o conceito interdisciplinaridade pelo fato de esse tema constar em ementas e programas? Os professores formadores são interdisciplinares em suas aulas? Eles dialogam com professores de outras áreas para em conjunto buscarem a superação da fragmentação do saber? A partir de resultados de algumas pesquisas, podemos inferir que, para a maioria das perguntas feitas anteriormente, a resposta seria negativa. 
Batista et al (2008), ao discutirem a implementação de projetos interdisciplinares no Ensino Médio, entrevistaram professores desse nível de ensino para compreender o entendimento deles sobre o assunto, e, nesse caminho, um dos aspectos analisados foi a formação do profissional. De acordo com os resultados publicados, apenas um dos entrevistados afirmou ter participado de experiências de trabalhos interdisciplinares na graduação. Sobre os outros entrevistados, os autores apresentam:

Os demais professores não destacaram experiências de trabalho interdisciplinar ou por meio de projetos em sua formação acadêmica, ou, caso tenham ocorrido, parece não ter ocupado um lugar de destaque, pois estes não mencionaram ações dessa natureza. $\mathrm{O}$ trabalho pedagógico desenvolvido por cada um caracterizou-se como essencialmente disciplinar e individualizado, e o mesmo aconteceu nas fases anteriores de escolarização, como indicou o professor M:

"[...] vim de uma escola em que cada matéria era separada, depois eu fui para a universidade onde o regime era semestral. Então, cada professor dava uma disciplina [...] não tinha a ver uma coisa com a outra [...]... tudo 'separadinho"'. (BATISTA et al, 2008)

Inserir de maneira efetiva a interdisciplinaridade na formação de professores demanda pensar o ensino interdisciplinar na formação inicial tanto a partir dos documentos que a norteiam quanto a partir das concepções dos que conduzem a efetivação das propostas pedagógicas. No caso dos documentos, temos as Diretrizes Curriculares Nacionais para a Formação de Professores da Educação Básica, em nível superior, curso de licenciatura, de graduação plena (BRASIL, 2002), que contemplam a articulação de conteúdos por meio da interdisciplinaridade, como observado no texto:

Parágrafo único. A aprendizagem deverá ser orientada pelo princípio metodológico geral, que pode ser traduzido pela ação-reflexão-ação e que aponta a resolução de situações-problema como uma das estratégias didáticas privilegiadas. Art. $6^{\circ} \mathrm{Na}$ construção do projeto pedagógico dos cursos de formação dos docentes serão consideradas: I - as competências referentes ao comprometimento com os valores inspiradores da sociedade democrática; II - as competências referentes à compreensão do papel social da escola; III - as competências referentes ao domínio dos conteúdos a serem socializados, aos seus significados em diferentes contextos e sua articulação interdisciplinar. (BRASIL, 2002) (grifo nosso)

No contexto da legislação, percebemos a indicação para que os cursos incluam nos seus projetos pedagógicos aspectos relacionados à abordagem interdisciplinar dos conteúdos. Tal indicação configura-se como necessária para adequar a formação de professores aos eixos mobilizadores da educação básica, dentre eles a contextualização e a interdisciplinaridade, pois, segundo Freitas (2002), "as referências e as bases de formação de professores vinculam-se estreitamente às exigências postas pela reforma educativa da educação básica, para a formação de novas gerações". 
Tendências para o ensino de química: o caso da interdisciplinaridade nos projetos pedagógicos das licenciaturas em química em Goiás

Em relação à interdisciplinaridade, os cursos de licenciatura em Química buscam a inserção desse aspecto formativo na formação inicial a partir do Projeto Pedagógico de Curso (PPC) tanto para se atenderem as orientações legais para a formação de professores quanto para se apresentar uma proposta atualizada e em consonância com o contexto da educação básica nacional. Ao tomarmos como objeto de estudo o PPC de um curso, podemos traçar um perfil do profissional a ser formado naquela instituição. Ao ser inquirido sobre seus saberes, o profissional deve ser capaz de identificar a postura epistemológica trabalhada na sua formação e a forma como se chega à concretização das transformações propostas no processo formativo.

Torna-se necessário esclarecermos neste ponto que o enfoque deste texto não é uma discussão conceitual ou epistemológica sobre a natureza do conhecimento interdisciplinar, pois, embora tal discussão seja de suma importância para a compreensão da interdisciplinaridade no contexto educacional, nosso enfoque se direciona à inserção da interdisciplinaridade nos documentos que apresentam as propostas pedagógicas para cursos de formação de professores de uma área específica do conhecimento. Dessa forma, no recorte feito para o desenvolvimento deste trabalho, consideramos importante apresentar nossa compreensão sobre o que seria a interdisciplinaridade aplicada à formação de professores de Química.

A partir dessa característica, a pesquisa apresentada buscou investigar a forma como se dá a inclusão das questões interdisciplinares nos textos dos PPCs, identificando a concepção de interdisciplinaridade que surge nos documentos e quais os caminhos apresentados para que a interdisciplinaridade seja implementada como aspecto formativo ao longo dos cursos.

\section{CARACTERIZAÇÃO DO MÉTODO: ANÁLISE TEXTUAL DISCURSIVA}

Para o desenvolvimento deste trabalho, buscamos, nos métodos utilizados na pesquisa qualitativa, um caminho fundamentado na ideia da análise textual discursiva. Moraes e Galiazzi (2007) caracterizam esse método da seguinte forma:

A análise textual discursiva pode ser entendida como o processo de desconstrução, seguido de reconstrução, de um conjunto de materiais linguísticos e discursivos, produzindo-se a partir disso novos entendimentos sobre os fenômenos e discursos investigados. Envolve identificar e isolar enunciados dos materiais submetidos à análise, categorizar esses enunciados e produzir textos, integrando nestes a descrição e interpretação, utilizando como base de sua construção o sistema de categorias construído. (MORAES; GALIAZZI, 2007, p. 112)

Segundo Moraes (2003), nessa abordagem, o processo analítico se dá a partir dos seguintes passos:

A) desmontagem dos textos, também chamada de unitarização dos textos: etapa na qual o material textual é desmontado em fragmentos que serão in- 
seridos em unidades que fazem parte do fenômeno;

B) estabelecimento de relações entre os dados extraídos, também chamada de categorização: etapa na qual são realizadas relações entre os dados extraídos, sendo eles combinados e classificados, para uma melhor compreensão, formando-se conjuntos mais complexos, que recebem o nome de categorias;

C) captação do novo emergente: etapa na qual outra compreensão do fenômeno em estudo é apresentada pelo pesquisador na forma de um novo texto que, neste caso, é o próprio texto da tese.

$\mathrm{Na}$ perspectiva do caminho metodológico exposto, a presente pesquisa se desenvolveu a partir da análise textual discursiva de PPCs de oito cursos de licenciatura em Química no estado de Goiás, sendo três cursos na capital e cinco cursos no interior entre instituições públicas e privadas. Elas foram nomeadas de 1 a 8 para efeito de identificação e análise neste trabalho. A escolha da análise textual discursiva a partir de documentos possibilitou-nos construir um perfil dos cursos de licenciatura em Química no Estado de Goiás e encontra-se respaldada na concepção de que os documentos personificam o currículo formal elaborado, representando o discurso oficial assumido pelos sujeitos que conduzem os processos educacionais no enfoque de nossa pesquisa.

Todas as etapas constitutivas do método foram seguidas: leitura pormenorizada dos documentos identificando referências ao nosso objeto de estudo, estabelecimento de relações para uma compreensão mais ampla do recorte em estudo e a elaboração de um novo texto a partir dessa nova compreensão da realidade. É importante salientarmos que os resultados apresentados neste artigo constituem-se como parte de uma tese de doutoramento que investigou diversos aspectos formativos inseridos nos projetos pedagógicos de licenciatura em Química. No entanto, neste artigo são discutidas apenas as análises referentes às questões sobre a interdisciplinaridade nos documentos. As categorias de análise a partir das quais pautamos nossas discussões foram: a concepcão de interdisciplinaridade nos documentos; e os caminbos propostos para a implementação da interdisciplinaridade ao longo do curso.

\section{TECENDO RELAÇÕES: A INTERDISCIPLINARIDADE NO CONTEXTO DA EDUCA- ÇÃO BÁSICA E NA FORMAÇÃO DE PROFESSORES}

Em relação à inserção da interdisciplinaridade no contexto formativo dos professores de ciências, Augusto et al (2004), ao investigarem tanto as concepções de docentes da área de Ciências Naturais sobre interdisciplinaridade quanto a forma como esses docentes desenvolveriam uma proposta interdisciplinar no ensino médio, ressaltam que "a questão interdisciplinar constitui-se em um dos eixos que sustenta a formação docente nesse nível”. Dessa forma, há a necessidade de que a interdisciplinaridade esteja inserida em propostas de formação de professores, contemplando-se não apenas as orientações normativas, mas também as 
Tendências para o ensino de química: o caso da interdisciplinaridade nos projetos pedagógicos das licenciaturas em química em Goiás

tendências atuais para a educação básica. Sob tal enfoque, Mello (2001) nos aponta que

Referenciada nas competências a serem constituídas na educação básica, a formação inicial dos professores para atuarem na mesma educação básica deve levar em conta os princípios pedagógicos estabelecidos nas normas curriculares nacionais: a interdisciplinaridade, a transversalidade e a contextualização, a integração de áreas em projetos de ensino, que constituem hoje mandados ou recomendações nacionais. (MELLO, 2001) (grifo nosso)

De acordo com as normativas legais (BRASIL, 2002), a articulação interdisciplinar precisa fazer parte da proposta pedagógica dos cursos de formação de professores. No entanto, a forma como tal contexto é inserido depende da visão dos sujeitos que elaboram o projeto pedagógico. Nesse sentido, a interdisciplinaridade na formação inicial de professores se orienta a partir da proposta interdisciplinar para a educação básica. Para Domingues et al (2000), apesar da vigência do paradigma disciplinar ainda ser bastante forte, a escola vive a constante tensão entre a cultura escolar e as experiências da vida humana nas quais a realidade é multidimensional, e, dessa forma, o ambiente escolar precisa "acreditar na possibilidade de integração das diferentes áreas do saber, agregando-as as diversidade culturais".

Um aspecto que precisa ser considerado em relação à inserção da interdisciplinaridade na educação básica é o fato de que a reforma curricular implementada a partir de 1990, que desenha novos rumos para a educação no Brasil, adota todo um discurso de formar o cidadão no contexto do mundo produtivo, ou seja, formar um cidadão para atender as demandas de um mundo capitalista, já que "a vida assume uma dimensão especialmente produtiva do ponto de vista econômico, em detrimento de sua dimensão cultural mais ampla" (LOPES, 2002). Dessa forma, eixos como contextualização, interdisciplinaridade e currículo por competências, discutidos por Lopes (2002), fazem parte de um discurso pedagógico e regulativo do processo educacional.

Ao associar as diretrizes da educação básica à formação docente, devemos estar atentos à criticidade do processo, pois, conforme salienta Zibas (2005), além de possibilitar o fortalecimento de perspectivas ideológicas conservadoras em relação aos discursos atrelados às teorias de do eficientismo social, "a interdisciplinaridade do método não pode ser confundida com a polivalência docente — polivalência que, para o ensino médio, só pode significar empobrecimento da transmissão do conhecimento". Assim, nossa pesquisa visa também a contribuir para o desvelar a respeito das concepções sobre interdisciplinaridade sobre as quais se norteiam as propostas pedagógicas de cursos de licenciatura em Química no estado de Goiás. 
Nyuara Araújo da Silva Mesquita | Márlon H. F. B. Soares

\section{CONCEPÇÃO DE INTERDISCIPLINARIDADE PRESENTE NOS DOCUMENTOS}

Em todos os documentos analisados, foram encontradas referências à necessidade da implementação da interdisciplinaridade como princípio formativo. Podemos observar isso nos trechos selecionados a seguir:

Nessa perspectiva, não se pode negar a necessidade de um trabalho interdisciplinar, que vá além dos limites de cada disciplina, com o intuito de desenvolver a crítica, a reflexão a partir da constatação de que todo conhecimento é produzido em um contexto social, econômico e político específico, que o mediatiza e condiciona, introduzindo a ideia de aprender a estabelecer e interpretar relações. (Instituição 4) (grifo nosso)

Assim, esta proposta dimensiona uma matriz curricular, numa perspectiva interdisciplinar, que permite a transversalidade e a contextualidade. (Instituição 1) (grifo nosso)

Fomentar o processo educacional visando o desenvolvimento do pensamento crítico-reflexivo, para a participação comunitária, para o aprimoramento do conhecimento científico, baseado na universalidade do conhecimento e na interdisciplinaridade. (Instituição 3) (grifo nosso)

Porém, em alguns casos, existe a contradição entre o que se propõe no documento e os caminhos para se atingirem tais objetivos. Mesmo sendo a interdisciplinaridade um dos eixos estruturadores dos projetos, a hierarquização dos conteúdos surge, em alguns documentos, como forma de organização das disciplinas.

O curso é estruturado em semestres, no sistema seriado, buscando interligar hierarquicamente os conteúdos, minimizando a compartimentalização. (Instituição 4) (grifo nosso)

O currículo abrange uma sequência de disciplinas ordenadas em semestres letivos. A forma de integralização curricular fundamenta-se no sequenciamento hierárquico de conteúdos. (Instituição 8) (grifo nosso)

Defendemos que a hierarquização dos conteúdos e disciplinas apresenta obstáculos para a construção interdisciplinar, pois compartimentaliza o conhecimento, constituindo-se como princípio antagônico dela. Dessa forma, o uso do termo "minimizando a compartimentalização", pela instituição 4, mostra-se em desacordo com a ideia de interdisciplinaridade sugerida no documento. De acordo com Bernstein (apud Veiga, 2004),

A organização curricular integrada trabalha o conhecimento com base em conceitos de interdisciplinaridade e de integração. As fronteiras entre os componentes curriculares são técnicas, uma vez que os conteúdos mantêm entre si uma relação aberta. Quando há integração, dissipa-se a hierarquia e estabelece-se uma prática comum de ensino. (BERNSTEIN apud VEIGA, 2004, p. 67) (grifo nosso).

É importante salientarmos que a ideia de que interdisciplinaridade e hi- 
erarquização são antagônicas não é um consenso, pois, de acordo com outros teóricos do assunto, a interdisciplinaridade configura-se a partir da coordenação das ações disciplinares, existindo um nível hierárquico superior (JAPIASSU, 1976; SANTOMÉ, 1998). Para esses autores, o modelo interdisciplinar constitui-se a partir de relações de parcerias estabelecidas entre as diferentes percepções da realidade que são elaboradas pelas disciplinas presentes no processo, existindo dois níveis diferentes, e a coordenação da construção dos saberes se dá a partir do nível superior.



Fonte: Japiassu (1976, p. 74)

Notamos que os quadrados representam os conteúdos ou as disciplinas envolvidas. Elas se relacionam entre si em um nível hierárquico, mas mantêm uma ligação com outro conceito de uma maneira cooperativa.

Podemos deixar mais clara essa perspectiva a partir de um exemplo de proposta interdisciplinar desenvolvida na educação básica. Guerra et al (1998) nos apresentam um projeto interdisciplinar que tem como enfoque central a discussão sobre energia no contexto do ensino de física. Porém diversos aspectos relacionados ao tema energia são discutidos à luz do contexto histórico do desenvolvimento científico e tecnológico da humanidade. Dessa forma, os conceitos científicos da Física podem ser considerados como balizadores da proposta interdisciplinar.

Em relação às diferentes concepções sobre interdisciplinaridade que, por um lado, consideram a importância da hierarquização e, por outro, afirmam que, se há interdisciplinaridade, dissipa-se a hierarquização, fizemos nossas escolhas como pesquisadores da área de ensino de Química e, no contexto analisado, entendemos que, ao enfatizar a hierarquização dos conteúdos, os documentos apresentam a possibilidade de se construir a ideia de que alguns conteúdos são mais importantes em relação a outros.

Dessa maneira, mesmo considerando que a formação e a futura atuação 
profissional sejam na área da docência em Química, para a formação do professor, enfatizamos que a ideia de interdisciplinaridade precisa estar vinculada à noção de diálogo entre saberes. Assim, um diálogo, pela própria concepção da palavra, consiste em conversação, troca de ideias e opiniões entre duas ou mais pessoas ou instâncias. Quando uma das partes envolvidas neste diálogo apresenta-se em um nível superior, a troca ou a interação pode ser influenciada e comprometida pela assimetria presente na relação. Se, no próprio projeto, não há clareza em relação à necessidade de integração e não de hierarquização, o discurso se constrói nos parâmetros do contexto atual da educação, mas as palavras se perdem no significado contraditório.

Dessa visão formativa a respeito da interdisciplinaridade, podem decorrer situações nas quais o professor de Química acha-se competente para discutir outros conceitos em suas aulas pelo fato desses conceitos serem abordados em seu curso. No entanto, podemos pensar que, nos cursos de Química, a Matemática, a Biologia ou a Física são ferramentas usadas para a compreensão dos conceitos químicos.

Logo, quando os licenciandos decidem trabalhar esses conceitos na sua prática docente por acreditarem estar desenvolvendo uma aula interdisciplinar, a metodologia pode se mostrar falha, pois eles não tiveram acesso durante sua formação inicial às questões pedagógicas referentes a esses conceitos, ou seja, à capacitação para optarem pela melhor forma didática e o recurso mais adequado para abordarem determinado conceito de Física, Biologia, Matemática, dentre outras disciplinas.

Um projeto pedagógico que vise à interdisciplinaridade como princípio formativo do futuro licenciado em Química precisa se pautar na questão de que esta se constitui como postura, tanto de atuação do professor formador, quanto nos direcionamentos que a organização curricular prevê a partir do seu projeto de curso. Postura não se limita a vontade, mas depende de todo um contexto formativo que não apenas se discuta o conceito ou se o exemplifique, mas em que, além disso, esse conceito seja tornado significativo no âmbito da prática docente dos próprios professores formadores em situações de ensino-aprendizagem.

Nos cursos de licenciatura em Química ainda persiste a falta de integração entre as próprias disciplinas que compõem as matrizes curriculares. Como podem os professores formadores trabalharem a interdisciplinaridade com seus alunos se a estrutura curricular do curso de formação inicial não contempla tal aspecto? Silva e Schnetzler (2008), ao investigarem concepções e ações de formadores de professores de Química, apontam que a dicotomia e a falta de integração disciplinar nos cursos de licenciatura em Química são usuais em nossos currículos de formação de professores, nos quais as disciplinas do núcleo específico são totalmente separadas das disciplinas do núcleo pedagógico, exceções feitas apenas para as disciplinas como Estágio ou Prática Curricular.

Dessa forma, adotar a interdisciplinaridade como eixo formativo em um 
PPC de licenciatura em Química significa, em princípio, inseri-la na própria estrutura curricular do curso possibilitando a integração dos saberes necessários à formação docente e, a partir dessa inserção, delinear caminhos e perspectivas pedagógicas que contemplem uma concepção menos compartimentalizada do conhecimento pertinente à formação inicial do licenciado em Química.

Argumentamos que não há uma receita pronta ou uma proposta específica que solucione a questão sobre como se estabelecer o contexto interdisciplinar na formação inicial do licenciado em Química, pois cada curso ou cada instituição precisa considerar sua realidade institucional, seu quadro de docentes, seu públicoalvo e suas reais necessidades formativas sem perder de vista o fato de que o primeiro passo para uma proposta pedagógica interdisciplinar passa por uma matriz curricular que possibilite a integração entre as disciplinas do curso em questão.

\section{CAMINHOS PROPOSTOS PARA A IMPLEMENTAÇÃO DA INTERDISCIPLINAR- IDADE AO LONGO DO CURSO}

Podemos notar que o uso da interdisciplinaridade como eixo norteador nos documentos não é justificado ao longo dos projetos, ou seja, a maioria das instituições não explica de que forma se efetivará uma formação docente interdisciplinar. A instituição 3 justifica seu caráter interdisciplinar a partir da capacitação pedagógica docente, em que,

No planejamento, dentro da semana pedagógica, o professor participa de reuniões de planejamento dos conteúdos, quando grupos de docentes (que ministram disciplinas no mesmo curso) interagem para criar e desenvolver práticas que promovam a interdisciplinaridade. (grifo nosso)

O planejamento é fundamental para o desenvolvimento de atividades interdisciplinares. Porém, sendo o PPC o documento que deve nos dizer quais os caminhos que norteiam o curso, torna-se necessário que esse documento seja mais específico em relação ao tema abordado. No caso dessa instituição, o trecho citado é o único que explicita a forma de abordagem interdisciplinar. Notamos que há um enfoque na interdisciplinaridade como saber que associa diversos conhecimentos, mas não como prática pedagógica.

De acordo com Batista e Salvi (2006), ao discutirem perspectiva pósmoderna e interdisciplinaridade educativa, "é necessário mostrar de maneira mais precisa a função e importância da adoção do enfoque interdisciplinar na construção do conhecimento durante os processos de ensino e de aprendizagem". Nesse sentido, propostas pedagógicas precisam ser mais claras para identificar ou delinear os caminhos a partir dos quais se concretizará uma formação interdisciplinar. Tal clareza pode ser contemplada a partir de alguns caminhos delineados no PPC para além da simples inserção textual da interdisciplinaridade nos documentos. 
Um dos caminhos seria a apresentação, nos projetos pedagógicos, da forma como a proposta interdisciplinar poderia ser concretizada ao longo do curso, ou seja, como o grupo de docentes pode contribuir no sentido de minimizar a compartimentalização dos saberes no processo ensino aprendizagem que envolve a construção do conhecimento científico. A integração das disciplinas pode ser realizada tanto a partir de disciplinas pertencentes ao mesmo campo epistemológico quanto por disciplinas relacionadas a outros cursos.

Sob tal aspecto, Pierson e Neves (2001) apresentam e discutem uma proposta integrativa com esse viés em cursos de formação de professores de Física e Biologia. De acordo com esses pesquisadores, apesar dos obstáculos existentes quando se tenta estabelecer o diálogo entre áreas do saber diferentes, há a necessidade de se explicitarem as diferentes visões de mundo no sentido de que "a tomada de consciência da posição do outro é um fator importante para possibilitar uma abertura para o diálogo, à medida que permite repensar a própria referência e perceber sua incompletude".

Em nossa investigação, observamos que somente o PPC da instituição 6, dentre os documentos analisados, explica, ou tenta explicar, de que forma se efetiva, durante o curso, uma formação interdisciplinar. Porém, podemos notar o uso de diversos termos que tornam confusa a justificativa:

Um dos princípios básicos presentes no Projeto Pedagógico do Curso de Licenciatura Plena em Química é a presença de mecanismos efetivos de interdisciplinaridade e de integração de conhecimentos para a construção das competências desejadas e de flexibilização e adaptabilidade curricular às mudanças ambientais. (Instituição 6) (grifo nosso)

Na continuação temos a maneira como é desenvolvida a formação interdisciplinar:

No curso de Licenciatura Plena em Química a interdisciplinaridade é trabalhada através de um livro paradidático, avaliação transversal, projeto interdisciplinar e por cada professor em suas respectivas disciplinas. (grifo nosso)

Aqui, notamos uma confusão em relação aos conceitos. O que nos parece é que o fato de um projeto ser desenvolvido por cada professor em sua disciplina configura-se mais como multidisciplinaridade do que como interdisciplinaridade. Segundo Piaget apud Santomé (1998), a multidisciplinaridade consiste em um nível inferior de integração e

Ocorre quando, para solucionar um problema, busca-se informação e ajuda em várias disciplinas, sem que tal interação contribua para modificá-las ou enriquecê-las. Esta costuma ser a primeira fase de constituição de equipes de trabalho interdisciplinar, porém não implica que, necessariamente, seja preciso passar a instâncias de maior cooperação. (PIAGET apud SANTOMÉ, 1998, p. 70) 
Tendências para o ensino de química: o caso da interdisciplinaridade nos projetos pedagógicos das licenciaturas em química em Goiás

Outro ponto de análise em relação ao tema é o fato de que a interdisciplinaridade é algumas vezes confundida com a contextualização. É certo que um ensino interdisciplinar pode ser contextual e vice-versa. Porém, não necessariamente, os dois termos constituem-se como sinônimos. A instituição 6 traz essa mescla entre estes dois conceitos, quando, ainda explicando o desenvolvimento da proposta interdisciplinar a partir do livro paradidático que gera um projeto transversal justifica:

\footnotetext{
Neste contexto, acredita-se que uma proposta de ensino por meio de projetos de pesquisa potencializa nossos alunos para uma verdadeira aprendizagem significativa. A utilização de temas associados à vida cotidiana e à região favorece a integração do estudante no curso, demonstrando ainda o potencial do mercado na absorção dos profissionais formados.
}

Argumentamos que os problemas de natureza conceitual observados nos projetos pedagógicos de cursos são provenientes da falta de uma linha teórica mais fundamentada em autores e pesquisadores da área de formação de professores. Isso pode ser concluído tanto pelos trechos citados anteriormente quanto pelo fato de que, dos documentos analisados, quatro deles não apresentaram seus referenciais bibliográficos ao final do documento, inclusive o da instituição 6 . Entre as quatro instituições que apresentaram seus referenciais, apenas uma faz as citações no corpo do texto. As demais apresentam nas referências dois ou três autores e os documentos oficiais usados como suporte para elaboração do PPC.

É importante referenciar um texto com autores da área, pois pessoas intelectualmente responsáveis pelas escolhas teóricas e metodológicas que vão nortear a proposta curricular de um curso de formação inicial de professores realizam tais escolhas respaldadas em vozes alheias, que, na interação com os pares, concretizam-se nos documentos que sintetizam ideias e ideais. Portanto, não podem se furtar ao compromisso de apresentar à comunidade acadêmica as fontes nas quais se estabeleceram e em que se construíram os caminhos traçados pelo grupo.

Pelo fato de esses documentos se originarem no meio acadêmico, precisam se pautar nos trâmites do mesmo. Além do mais, o uso de referenciais teóricos, provavelmente, evitaria a reunião artificial de ideias ou conceitos de origens disparatadas que não contribuem para a melhoria da qualidade da formação de professores de Química.

\section{CONSIDERAÇÕES FINAIS}

A análise realizada a partir dos PPCs dos cursos de licenciatura em Química no estado de Goiás nos apontou que o princípio formativo considerado - em nosso caso, a interdisciplinaridade - é apresentado de maneira contraditória aos referenciais teóricos que abordam o tema e que, na tentativa de se inserirem 
no contexto atual da educação, os documentos apresentam a interdisciplinaridade como um dos eixos de suas propostas pedagógicas, mas não oferecem suporte teórico nem indicam os caminhos metodológicos para tal adequação.

$\mathrm{Na}$ tentativa de adequar as propostas expressas nos documentos a alguns aspectos considerados na elaboração das diretrizes para a educação básica, como interdisciplinaridade, algumas instituições se apropriam de determinados termos sem, no entanto, apresentarem conhecimento em relação aos conceitos dos quais fazem uso. Disto resultam sincretismos que podem comprometer as propostas no sentido de torná-las contraditórias em seu próprio contexto.

Toda essa apropriação de termos considerados atuais para as tendências de formação de professores se torna sem sentido a partir do momento em que se contradiz em sua própria viabilidade de execução. Finalizamos esta exposição fazendo um convite à reflexão sobre a problemática aqui apresentada e ressaltamos que, ao partirmos do significado da palavra "projeto", de origem latina, em que está contida uma intenção de algo que pode vir a ser e, simultaneamente, direciona ações para que uma proposta se concretize, consideramos que os caminhos podem sempre ser refeitos.

Dessa forma, os projetos não são fixos ou imutáveis, mas podem ser reelaborados a partir das necessidades de atualização e adequação dos cursos. É neste contexto de reelaboração que o presente trabalho pretende contribuir para que possamos ponderar e refletir sobre a construção de propostas coerentes, em que seja minimizada a distância entre o discurso oficial, suas possibilidades de efetivação e a construção de uma identidade para a formação inicial de professores de Química.

\section{BIBLIOGRAFIA}

AUGUSTO, T. G. M. et al. Interdisciplinaridade: concepções de professores da área Ciências da Natureza em formação em serviço. Ciência \& Educação, v. 10, n. 2, p.277-289, 2004.

BATISTA, I. L; LAVAQUI, V; SALVI, R. F. Interdisciplinaridade escolar no Ensino Médio por meio de trabalho com projetos pedagógicos. Investigações em Ensino de Ciências, v. 13, n. 2, p.209-239, 2008.

BATISTA, I. L, SALVI, R. F. Perspectiva pós-moderna e interdisciplinaridade educativa: pensamento complexo e reconciliação integrativa. Ensaio, Belo Horizonte, v. 8, n. 2, p.147159, 2006.

BRASIL, Resolução CNE/CP No 1, de 18 de Fevereiro de 2002. Disponível em: < http:/ /portal.mec.gov.br/seesp/arquivos/pdf/res1_2.pdf>. Acesso em: 09 de janeiro de 2009.

BERNSTEIN, B. Clases, códigos y control: hacia uma teoria de lãs transmisiones educativas. Madri: Akal, 1988 apud Veiga, I. P. In: Educação Básica e Educação Superior: Projeto Político-Pedagógico. Campinas, SP: Papirus, 2004. 
Tendências para o ensino de química: o caso da interdisciplinaridade nos projetos pedagógicos das licenciaturas em química em Goiás

CARLOS, J. G. Interdisciplinaridade no Ensino Médio: desafios e potencialidades. 2007. 139p. Dissertação (Mestrado Profissionalizante em Ensino de Ciências) - Universidade de Brasília, Brasília, 2007.

DOMINGUES, J. J. TOCHI, M. S. OLIVEIRA, J. F. A reforma do Ensino Médio:a nova formulação curricular e a realidade da escola pública. Educação \& Sociedade, n. 70, p.63-79, 2000.

FAZENDA, I. C. A. Interdisciplinaridade: história, teoria e pesquisa. Campinas, SP: Papirus, 2001. FREITAS, H. C. L. Formação de professores no Brasil: 10 anos de embate entre projetos de formação. Educação e Sociedade, v. 23, n. 80, p. 136-167, 2002.

GUERRA, A. FREITAS, J. BRAGA, M. A. A interdisciplinaridade no ensino das ciências a partir de uma perspectiva histórico-filosófica. Cad.Cat.Ens.Fís., v. 15, n. 1: p. 32-46, 1998.

JAPIASSU, H. Interdisciplinaridade e patologia do saber. Rio de Janeiro: Editora Imago, 1976. LOPES, A. C. Os Parâmetros Curriculares Nacionais para o Ensino Médio e a submissão ao mundo produtivo: o caso do conceito de contextualização. Educação \& Sociedade, v. 23, n. 80, p. 386-400, 2002.

MELLO, G. N. Formação inicial de professores para a educação básica: uma (re)visão radical. Revista Ibero-Americana de Educación, n. 25, p. 147-174, 2001.

MORAES, R. Uma tempestade de luz: a compreensão possibilitada pela análise textual discursiva. Ciência e Educação, v. 9, n. 2, p. 191-211, 2003.

MORAES, R. e GALIAZZI, M. C. Análise textual discursiva. Ijuí: Editora Unijuí, 2007. PIERSON, A. H. C. NEVES, M. R. Interdisciplinaridade na formação de professores de ciências: conhecendo obstáculos. Revista brasileira de Pesquisa em Educação em Ciências, v. 1, n. 2, p. 120-131, 2001.

PIAGET, J. La epistemologia de las relaciones interdisciplinares. In APOSTEL, L. BERGER, G. BRIGGS, A. e MICHAUD, G. Interdisciplinariedad: problemas de la enseñanzay de la investigaciõn en las universidades, México: Associación Nacional de Universidades e Institutos de Enseñanza Superior, 1979 apud SANTOMÉ, J. T. Trad. Cláudia Schilling. Globalização e interdisciplinaridade: o currículo integrado. Porto Alegre: Artes Médica, 1998. SANTOMÉ, J. T. Trad. Cláudia Schilling. Globalização e interdisciplinaridade: o currículo integrado. Porto Alegre: Artes Médica, 1998.

SILVA, R. M. G. SCHNETZLER, R. P. Concepções e ações de formadores de professores de química sobre o estágio supervisionado: propostas brasileiras e portuguesas. Química Nova, v. 31, n. 8, p. 2174-2183, 2008.

VEIGA, I. P. Educação Básica e Educação Superior: Projeto Político-Pedagógico. Campinas, SP: Papirus, 2004.

ZIBAS, D. M. L. A reforma do Ensino Médio nos anos de 1990: o parto da montanha e as novas perspectivas. Revista Brasileira de Educação, n. 28, p. 24-37, 2005.

Data de recebimento: 08/07/2010

Data de aprovação: 16/12/2011

Data da versão final: 21/10/2011 